\title{
Cobalt oxide-iron oxide selective coatings for high temperature applications
}

\author{
C S UMA, L K MALHOTRA and K L CHOPRA \\ Department of Physics, Indian Institute of Technology, New Deihi 110016, India \\ MS received 1 January 1985; revised 9 January 1986
}

\begin{abstract}
Cobalt oxide-iron oxide coatings on stainless steel have been prepared by spray pyrolysis technique. These coatings have absorptance $(\alpha)=0.94$ and emittance $\left(\varepsilon_{100}\right)=0.20$ which are much better values than for cobalt oxide or iron oxide alone on stainless steel substrates. The coatings have been found to be stable for temperatures upto $400^{\circ} \mathrm{C}$.
\end{abstract}

Keywords. Selective coatings; absorptance; emittance; cobalt-iron oxide

\section{Introduction}

The spectral profile of an ideal absorber surface in a photothermal converter for solar spectrum comprises of a low reflectance region from $0 \cdot 3-2 \cdot 0 \mu \mathrm{m}$ and a high reflectance at higher wavelength. Such a spectral profile can be generated in many ways by using a combination of thin film materials (selective coatings). An absorber-reflector tandem structure is one of the important selective coatings. The tandem structure is made up of a thin layer of a material (which absorbs the solar radiation but is transparent in infrared) on a metal having a high infrared reflectance and hence low emittance.

Cobalt oxide as an absorber layer has been studied by many workers (Kok oropoulas et al 1959; Gillette 1960; Kruidhoff and Van der Leij 1979; McDonald 1980; Smith et al 1980; Chidambaram et al 1982) on a variety of substrates like polished nickel, silver, platinum and stainless steel. Different techniques such as thermal oxidation, electrodeposition and spray pyrolysis have been utilized to deposit thin cobalt oxide layers. The resulting absorber/reflector tandem structure gives integrated absorptance in the range $0.87-0.92$ and thermal emittance $\sim 0.14-0.24$. The reflectance spectrum of such an oxide coating on metal substrate shows a rise around $1.05 \mu \mathrm{m}$ which limits the ultimate integrated absorptance. Addition of other materials like cobalt sulphide (Chidambaram et al 1982) modifies the reflectance spectrum but the presence of sulphide reduces the stability of the coating to $\sim 250^{\circ} \mathrm{C}$. If this modification is achieved by the addition of another stable oxide, a higher stability is expected. Such a combination of cobalt oxide-iron oxide was studied by Kruidhoff and Van der Leij (1980) by thermally oxidizing an electroplated layer of $\mathrm{Fe}$ and $\mathrm{Co}$. Iron oxide has lower refractive index compared to cobalt oxide and hence one expects such a combination to give rise to a high absorptance. However, an integrated absorptance of only 0.90 and thermal emittance of 0.3 was obtained by these workers. The coatings were found to be stable up to $300 \mathrm{C}$. In the present work a simple spray process has been used to prepare cobalt oxide-iron coatings on stainless steel. The results are presented in the following section. 


\section{Experimental details}

The coatings were prepared by spray pyrolysing aqueous solution of cobalt nitrate and ferric nitrate on stainless steel substrates. The substrates were initially cleaned by a mild scrubbing with detergent, thoroughly washed with water and then chemically etched for $2-3 \mathrm{~min}$ at $60^{\circ} \mathrm{C}$ in a solution having $200-250 \mathrm{~g} / \mathrm{l}$ of sodium dichromate and $20-30 \mathrm{ml} / 1$ of sulphuric acid. This was followed by cleaning with distilled water. Good, uniform and adherent coatings were obtained at a deposition temperature of $\sim 170^{\circ} \mathrm{C}$. Various parameters like volume of the solution sprayed, concentration of cobalt nitrate and ferric nitrate solution, spray rate were optimized to give the best values of absorptance and emittance.

Total reflectance was measured using a Hitachi 330 spectrophotometer with an integrating sphere attachment. Freshly prepared $\mathrm{MgO}$ was used as a standard. The absorptance $(\alpha)$ was calculated by integrating the reflectance data over AM 1.5 spectrum. The emittance $(\varepsilon)$ was measured by using the standard radiometric method. The temperature of measurement was kept at $100^{\circ} \mathrm{C}$. The stability of the coating was tested by annealing in air at $400^{\circ} \mathrm{C}$ and $500^{\circ} \mathrm{C}$ for $24 \mathrm{hr}$ and in a separate test, by boiling in a $5 \% \mathrm{NaCl}$ solution. The absorption and emittance were measured before and after each test.

Electron diffraction analysis was carried out using AEI/EM 802 transmission electron microscope. A scanning auger microprobe (PHI 590A) was used to determine the composition of the coating.

\section{Results and discussion}

Figure 1 shows the reflectance spectra of cobalt oxide, iron oxide and cobalt oxide-iron oxide coatings on stainless steel. The deposition parameters for all the coatings have

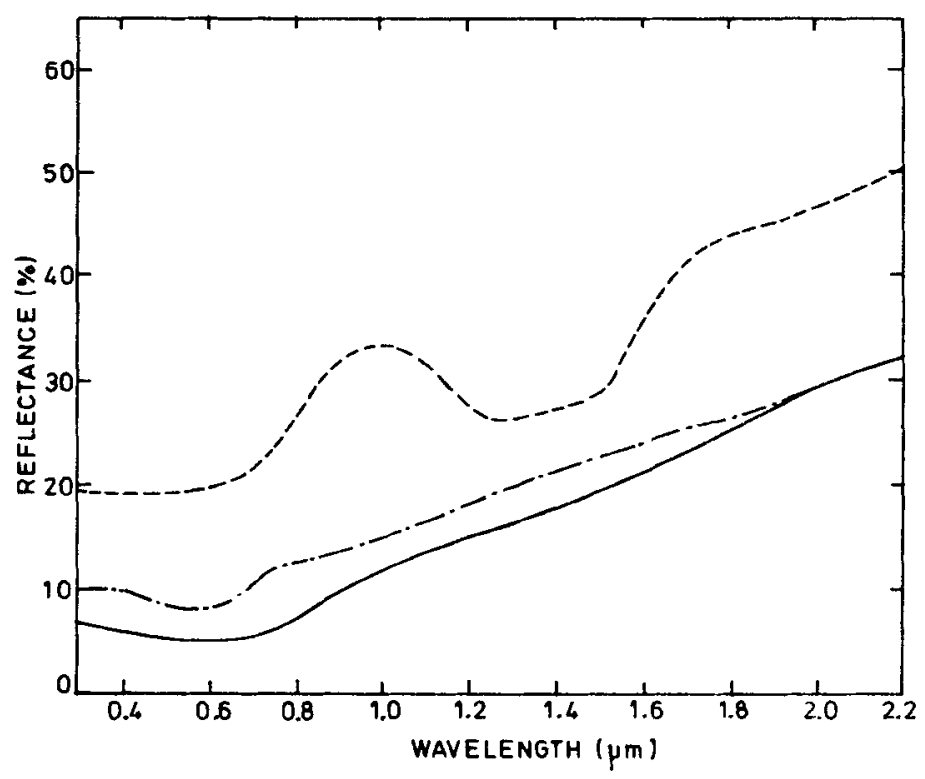

Figure 1. Reflectance spectrum of cobalt oxide (-- - ) , cobalt oxide-iron oxide (and iron oxide (-...- $)$ for the same deposition parameters. 
been kept similar for comparison. The characteristic rise in reflectance spectrum of cobalt oxide is quite evident. The coating with this reflectance spectrum has $\alpha=0.80$ only and $\varepsilon_{100} \sim 0.15$. The optimized values of $\alpha$ and $\varepsilon$ for cobalt oxide/stainless steel were 0.89 and 0.2 respectively. Since iron-oxide has a lower refractive index than cobalt oxide, one expects cobalt oxide-iron oxide coatings to have lower reflectance and hence higher absorptance. Incorporation of iron oxide thus decreases the reflectance in the entire spectral range of interest and particularly around $1.05 \mu \mathrm{m}$ and consequently $\alpha$ goes up to 0.94 . The emittance has a value of 0.20 . The reflectance spectrum of iron oxide alone is also shown. This coating has $\alpha=0.89$. This indicates that the higher absorption in cobalt-oxide iron oxide is partly due to the inherent low reflectance of this material compared to either cobalt oxide or iron oxide and partly due to textural effects. Dependance of absorptance and emittance on the volume of solution sprayed (and hence the thickness of the absorber layer) for a particular concentration is shown in figure 2 . The absorption initially rises and then saturates to a value of 0.94 . This value is limited by the front surface reflection of the absorber layer. As expected, emittance increases with thickness of the absorber layer.

The coatings were stable upto $400^{\circ} \mathrm{C}$. When heated upto $500^{\circ} \mathrm{C}$ in air for $24 \mathrm{hr}$, the absorptance decreased to 0.91 and emittance increased to 0.22 . The reflectance spectrum of such a heated sample is shown in figure 3 .

Auger analysis showed the presence of $\mathrm{Fe}, \mathrm{Co}$ and $\mathrm{O}$. The composition profile as a function of etch time is shown in figure 4. The ion etching was done using a differentially pumped ion gun with $\mathrm{Ar}^{+}$ions (ion beam voltage $\sim 3 \mathrm{KV}$, current density $\sim 600 \mu \mathrm{Amp} / \mathrm{cm}^{2}$, raster area $2 \mathrm{~mm} \times 2 \mathrm{~mm}$, corresponding to a precalibrated etch rate of $120 \mathrm{~A} / \mathrm{min}$ of $\mathrm{Ta}_{2} \mathrm{O}_{5}$ ). The depth profile was started after sputter cleaning. The percentage of iron was greater than that of cobalt throughout the film. Electron diffraction studies showed these coatings to consist of $\mathrm{Fe}_{2} \mathrm{O}_{3}$ and $\mathrm{CoO}$ with slight traces of $\mathrm{Fe}_{3} \mathrm{O}_{4} . \mathrm{Fe}_{2} \mathrm{O}_{3}$ and $\mathrm{CoO}$ are known to be the stable oxide of $\mathrm{Fe}-\mathrm{O}$ and $\mathrm{Co}-\mathrm{O}$ systems. The general decomposition mechanism of aqueous solution of salts is similar

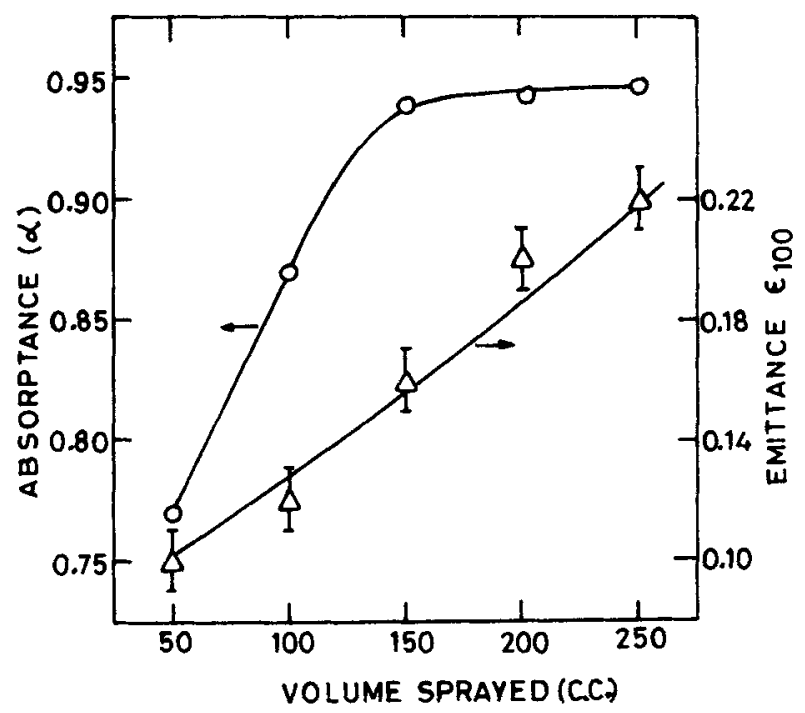

Figure 2. Dependance of absorptance and emittance on the amount of absorptance and emittance on the amount of volume of solution sprayed. 


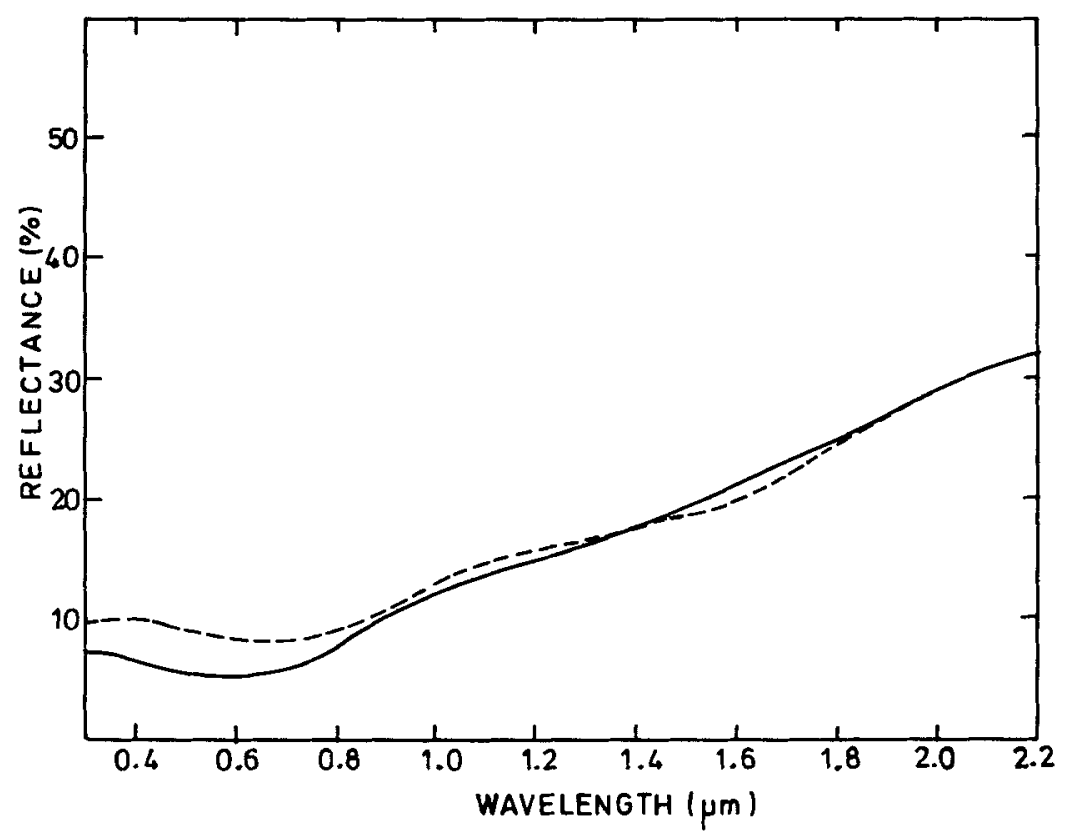

Figure 3. Change in reflectance spectrum of cobalt oxide-iron oxide coating on stainless steel after heating (-- - ) at $500^{\circ} \mathrm{C}$ for $24 \mathrm{hr}$ in air. (- - ) is reflectance spectrum before heating.

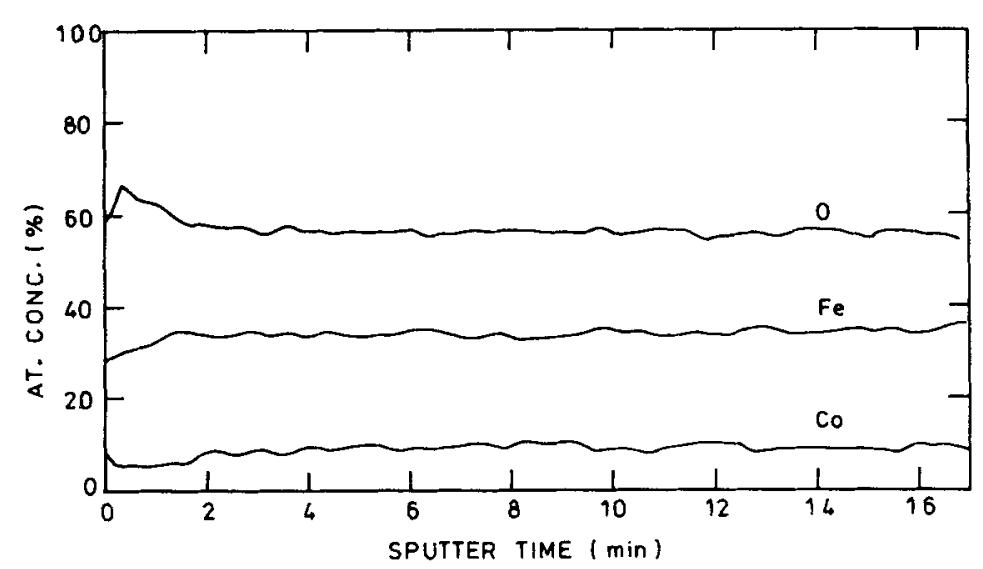

Figure 4. Auger depth profile showing the variation of $\mathrm{Fe}$, $\mathrm{Co}$ and $\mathrm{O}$ concentrations with depth.

to that of decomposition of salts in air. The following chemical reactions lead to the formation of $\mathrm{CoO}$ and $\mathrm{Fe}_{2} \mathrm{O}_{3}$.

$$
\begin{aligned}
& 2 \mathrm{Co}\left(\mathrm{NO}_{3}\right)_{2}-2 \mathrm{CoO}+4 \mathrm{NO}_{2}+\mathrm{O}_{2} \\
& 4 \mathrm{Fe}\left(\mathrm{NO}_{2}\right)_{3}-2 \mathrm{Fe}_{2} \mathrm{O}_{3}+12 \mathrm{NO}_{2}+3 \mathrm{O}_{2}
\end{aligned}
$$

This explains the presence of the above mentioned oxides in the bulk of the coating. 


\section{Conclusions}

Mixed oxides of cobalt and iron have been prepared on stainless steel by spray pyrolysis. The integrated absorptance of the mixed oxide is 0.94 which is higher than that of either cobalt oxide $(\alpha=0.80)$ or iron oxide $(\alpha=0.89)$ on stainless steel obtained under similar conditions. The emittance increases slightly from 0.15 for pure cobalt oxide to $0 \cdot 20$ for mixed oxide. As far as stability is concerned, cobalt oxide coatings are stable upto $600^{\circ} \mathrm{C}$ whereas the mixed oxide coatings of cobalt and iron are stable only upto $400^{\circ} \mathrm{C}$.

\section{References}

Chidambaram K, Malhotra L K and Chopra K L 1982 Thin Solid Films 87365

Chaudhary C and Sehgal H K 1982 Solar Energy 2825

Gillette R B 1960 Solar Energy 424

Kokoropoulos P, Salam E and Daniels F 1959 Solar Energy 319

Kruidhof W and Van der Leij M 1979 Solar Energy Mater. 269

McDonald G E 1980 Thin Solid Films 7283

Smith G B, Ignatiev A and Zajac G 1980 J. Appl. Phys. 514186 